\title{
Management of the polyallergic patient with allergy immunotherapy: a practice-based approach
}

Pascal Demoly ${ }^{1,2^{*}}$, Giovanni Passalacqua ${ }^{3}$, Oliver Pfaar ${ }^{4,5}$, Joaquin Sastre ${ }^{6}$ and Ulrich Wahn ${ }^{7}$

\begin{abstract}
Background: The great majority (60-80 \%) of patients consulting specialist physicians for allergic respiratory disease are polysensitized and thus may be potentially clinically polyallergic. However, management approaches to allergen immunotherapy (AIT) in polysensitized and polyallergic patients are not standardized.
\end{abstract}

Methods: An international group of clinicians with in-depth expertise in AIT product development, clinical trials and clinical practice met to generate up-to-date, unambiguous, pragmatic guidance on AIT in polysensitized and polyallergic patients. The guidance was developed after reviewing (1) the current stance of regulatory bodies and learned societies, (2) the literature data on single- and multi-AIT and (3) the members' confirmed clinical experience with polysensitized patients.

Results: AIT is safe and effective in polysensitized and polyallergic patients, and should always be based on the identification of one or more clinically relevant allergens (based on the type and severity of symptoms, the duration of induced symptoms, the impact on quality of life and how difficult an allergen is to avoid). Single-AlT is recommended in polyallergic patients in whom one of the relevant allergens is nevertheless clearly responsible for the most intense and/or bothersome symptoms. Parallel 2-allergen immunotherapy or mixed 2-allergen immunotherapy is indicated in polyallergic patients in whom two causal relevant allergens have a marked clinical and QoL impact. In parallel 2-allergen immunotherapy (whether subcutaneous or sublingual), high-quality, standardized, single-allergen formulations must be administered with an interval of 30 min. Mixing of allergen extracts may be considered, as long as (1) the mixture is technically feasible, (2) the mixture is allowed from a regulatory standpoint, (3) the allergen doses are reduced in proportion to the number of components but are still at concentrations with demonstrated efficacy.

Conclusions: Physicians can prescribe AIT (preferably with high-quality, standardized, single-allergen formulations) with confidence in polysensitized and polyallergic patients by focusing on clinical/QoL relevance and safety.

Keywords: Allergen immunotherapy, Allergy, Polyallergy, polysensitization, multi-allergen, single-allergen practice

\section{Background}

Allergic respiratory disease is a global health problem that seriously affects the sufferers' daily lives [1-6]. Individuals with clinical symptoms of IgE-driven allergic respiratory disease will have specific IgE to disease triggering allergens as evidenced by skin prick tests (SPTs) or serum specific immunoglobulin E (ssIgE) assays. In surveys of the general population in Europe and the USA

\footnotetext{
${ }^{*}$ Correspondence: pascal.demoly@inserm.fr

${ }^{1}$ Division of Allergy, Department of Pulmonology, Hôpital Arnaud de

Villeneuve, University Hospital of Montpellier, Montpellier, France

Full list of author information is available at the end of the article
}

(performed with standard panels of allergens), polysensitization is generally more prevalent than monosensitization $[7,8]$. In the first European Community Respiratory Health Survey, $12.8-25.3 \%$ of the participants were polysensitized [7]. Similarly, the National Health and Nutrition Examination Surveys in the US found that $38.8 \%$ of the participants were polysensitized [8].

Unsurprisingly, the great majority (60-80 \%) of patients consulting allergists are polysensitized [9-12]. The prevalence of polysensitization increases with age [12-14], with $54 \%$ in children under 11 years, $61.7 \%$ in adolescents and $64.8 \%$ in adults $(\mathrm{p}<0.001)$ in the French 
ODISSEE study, for example [12]. Longitudinal birth cohort studies (such as the Multicenter Allergy Study in Germany [15], the Manchester Asthma and Allergy Study in the UK $[16,17]$ and the Barn Allergy Milieu Stockholm Epidemiology study in Sweden [18]) have shown that polysensitization is a risk factor for the subsequent development of allergic diseases in general and allergic asthma (AA) in particular. Polysensitization also impacts the clinical expression of the disease; the greater the number of sensitizations, the more severe the allergic disease [19]. Asthma is more likely to be associated with allergic rhinitis (AR) in polysensitized patients than in monosensitized patients [12].

However, a polysensitized patient does not necessarily have polyallergy, whereas a polyallergic patient is necessarily polysensitized. Polyallergy is defined as a documented, causal relationship between exposure to two or more specific, sensitizing allergens and the subsequent occurrence of relevant clinical symptoms of allergy (Table 1). Once polyallergy has been diagnosed, the physician's next challenge is to decide (in collaboration with the patient) on a treatment strategy.

According to recent guidelines from the International Collaboration in Asthma, Allergy and Immunology [20], allergen immunotherapy (AIT) is indicated for the treatment of moderate-to-severe intermittent or persistent symptoms of AR-especially in those who do not respond well to pharmacotherapy. However, in the recently updated WAO position paper [6] on sublingual allergen immunotherapy (SLIT), failure of pharmacological treatment is not an essential prerequisite, and SLIT may be considered as an initial treatment for AR, in association with pharmacotherapy. We also consider that there are three additional indications for AIT: (a) the wish to avoid constant or long-term pharmacotherapy, (b) poor tolerability of symptomatic medications and (c) the wish to achieve a "cure" and possibly prevent disease progression (e.g. the development of new sensitizations and/or asthma) [21].

\section{Methods}

Clinical practice in the diagnosis of respiratory allergy and its management with AIT vary from one country to another. When AIT is prescribed, some allergists tend to treat the polyallergic patient with a single-allergen formulation (using the most clinically relevant allergen), whereas others prefer to prescribe either a mixture of two or more allergen extracts or two or more separate allergens [22]. Several publications have sought (to a lesser or greater extent) to address the management of the

Table 1 Definitions

\begin{tabular}{|c|c|}
\hline Term & Definition \\
\hline Allergen sources & $\begin{array}{l}\text { Allergen sources are allergens from the same homologous group (e.g. Dermatophagoides pteronyssinus and } \\
\text { Dermatophagoides farinae) }\end{array}$ \\
\hline Monosensitization & $\begin{array}{l}\text { Sensitization (according to standardized SPTs or sslgE assays) to only one of the allergens tested in the patient } \\
\text { to date. A single "allergen" is defined in allergists' terms, i.e. grass pollen, tree pollen, house dust mite, cat } \\
\text { dander (even though extracts of these extracts contain tens, hundreds or even thousands of different } \\
\text { polypeptides) }\end{array}$ \\
\hline Polysensitization & Sensitization (according to standardized SPTs or sslgE assays) to two or more allergens \\
\hline Monoallergy & $\begin{array}{l}\text { Clinically confirmed allergy to a single, sensitizing allergen (i.e. a causal relationship between exposure to the } \\
\text { sensitizing allergen and clinical allergy symptoms) }\end{array}$ \\
\hline Polyallergy & $\begin{array}{l}\text { Clinically confirmed allergy to two or more sensitizing allergens (i.e. causal relationships between exposure to } \\
\text { two or more sensitizing allergens and clinical allergy symptoms) }\end{array}$ \\
\hline Homologous group & $\begin{array}{l}\text { A group of allergens with (1) comparable physicochemical and biological properties of the source material, } \\
\text { (2) cross-reactivity/structural homology of the allergens, (3) identical formulation of the finished product, } \\
\text { and (4) identical production process of the allergen extract and of the finished product, as defined by the } \\
\text { European Medicines Agency }\end{array}$ \\
\hline Allergen mixture & $\begin{array}{l}\text { A single formulation containing a mixture of several allergen sources (e.g. a grass pollen source mixed with a } \\
\text { birch pollen source) }\end{array}$ \\
\hline Single-allergen immunotherapy & $\begin{array}{l}\text { Administration of an allergen immunotherapy formulation containing a single allergen source } \\
\text { In the cases of sequential administration of two consecutive single-allergen immunotherapies.(e.g. } 3 \text { years of } \\
\text { treatment with a house dust mite source, followed by } 3 \text { years of treatment with a grass pollen source) this } \\
\text { does not constitute multi-allergen immunotherapy (see below) }\end{array}$ \\
\hline Multi-allergen immunotherapy & $\begin{array}{l}\text { Administration of different allergen sources } \\
\text { Multi-allergen immunotherapy can be administered either in parallel (see below) or on a mixed formulation } \\
\text { (see below) }\end{array}$ \\
\hline Parallel multi-allergen immunotherapy & $\begin{array}{l}\text { The separate administration of two or more single-allergen immunotherapy formulations in parallel during the } \\
\text { same course of treatment }\end{array}$ \\
\hline Mixed multi-allergen immunotherapy & The administration of an allergen mixture (i.e. a single formulation containing several allergen sources) \\
\hline
\end{tabular}


polyallergic patient $[11-13,19,23-27]$ and the principles governing production and quality issues when mixing allergens in AIT preparations [27] but do not provide comprehensive, consensual, practical guidance.

Hence, we have designed a focussed, practice-based approach to the management of polyallergic patients. The objective of the present document is to provide physicians with clear, up-to-date, unambiguous, pragmatic, clinically relevant guidance on their day-to-day practice. To do so, we constituted an international group of renowned clinicians with in-depth expertise in AIT product development, clinical trials and clinical practice. The group developed consensual, unambiguous, pragmatic guidance on AIT in polysensitized monoallergic or polyallergic patients on the basis of (1) the literature data, (2) learned societies' and regulatory agencies' stances on the formulation and clinical use of multiple allergen immunotherapy (multi-AIT, such as a formulation containing two or more allergen extracts), and (3) the members' confirmed clinical experience with polysensitized patients. The aim is to give clear-cut answers to the most frequent questions raised by practitioners and patients. However, these recommendations are not intended to replace a clinician's clinical judgement and must to be adapted to suit each individual patient.

\section{Treatment of the polyallergic patient: a high-priority topic}

Before presenting our recommendations, we first consider (1) the current stance of regulatory bodies and learned societies regarding multi-AIT, (2) the clinical trial evidence in favour of multi-AIT and (3) evidence from observational studies conducted in physicians' practices or in the general population.

\section{What is the regulatory authorities' current stance on the composition of AIT formulations?}

The European Medicines Agency (EMA) has published general guidelines for manufacturers on the preparation and composition of allergen extracts and mixtures of extracts [28]. We were unable to find any guidance from other agencies around the world, including the US Food and Drug Administration. The EMA guidelines are based on the principle of homologous groups, which notably takes account of the physicochemical and biological characteristics of allergen extracts (Table 2). The EMA recommends that allergists should mix non-related allergens as little as possible and should not mix seasonal and perennial allergens or allergens with proteolytic activity (such as extracts of HDMs, moulds and insects) without justification. Mixing allergens clearly has an impact on pharmaceutical parameters (stability and dosing) and clinical effects (optimal dose and safety). The EMA's "homologous group" principal requires (1) description of the source materials' physicochemical and biological properties, (2) definition of the allergens' cross-reactivity and structural homology, (3) preparation of identical formulations of the final product, and (4) a guarantee that the extract's production process does not vary. The homologous groups generally correspond to taxonomic families. Within a given homologous group, allergen extracts will be very similar in terms of the composition, the source material's physicochemical and biological properties, the allergens' structural homology (and thus cross-reactivity) and the production process [28]. Further details on the rationale (based primarily on protein sequence data and cross-reactivity) for the six suggested homologous groups have been published (Table 2) [29]. The EMA document states that "to a limited extent, data on quality, safety and efficacy can be extrapolated from the representative source to other members of the homologous group"; for example, clinical data on birch allergen extracts can be extrapolated to other Betulaceae, such as the alder [28]. However, it is not possible to extrapolate efficacy results from one homologous group to another or from a homologous group to allergens that cannot be included in a homologous group; for example, clinical data on birch cannot be extrapolated to cypress. The EMA insists that the number of allergen extracts in a mixture should be kept to a minimum (regardless of the homology/cross-reactivity of the individual extracts) and that the number and relative proportions of the individual active substances must be justified. Mixtures containing allergens that do not belong to the same homologous group must always be justified [28].

\section{What are the current guidelines from learned societies on the management of polyallergic patients?}

Recommendations from the GA ${ }^{2}$ LEN/EAACI [23] clearly state that the number of sensitizations itself is less important than the clinical relevance of each allergen. In fact, a personalised approach should be based on the identification of the clinically relevant allergen and should consider the type and severity of symptoms, the longest duration of induced symptoms over the year, the greatest impact on quality of life (QoL) and how difficult an allergen is to avoid. When considering the composition of AIT formulations, the GA ${ }^{2} \mathrm{LEN} / \mathrm{EAACI}$ guidelines do not recommend mixtures [23]. The Allergic Rhinitis in Asthma (ARIA) guidelines have continuously put forward the same principles [2-4]. The US AIT practice parameters have moved in the same direction [30]; the third update emphasizes that it is important to treat the patients only with relevant allergens. None of these guidelines, however, gives pragmatic recommendations on how clinicians can identify and manage polyallergic patients in their daily practice. 
Table 2 The homologous groups suggested by the EMA [28] and Lorenz et al. [29]

\begin{tabular}{|c|c|c|c|}
\hline \multicolumn{2}{|l|}{ Homologous groups } & \multicolumn{2}{|l|}{ No homologous groups } \\
\hline \multicolumn{4}{|l|}{ Tree pollen } \\
\hline \multicolumn{2}{|c|}{ 1. Suggested homologous group: birch/fagales } & \multicolumn{2}{|c|}{ Non-grouped species: justification for mixing required } \\
\hline Betula verrucosa $=B$. pendula $a^{*}=B$. alba & European white birch & Fagus sylvatica & European beech \\
\hline Alnus glutinosa & Alder & Acer sp. & Maple \\
\hline Carpinus betulus & Hornbeam & Platanus sp. & Plane tree \\
\hline Corylus avellana & Hazel & Populus sp. & Poplar \\
\hline Quercus alba & Oak & Robinia pseudoacacia & False acacia, locust tree \\
\hline \multirow[t]{4}{*}{ Castanea sativa } & Sweet chestnut & Salix sp. & Sallow/willow \\
\hline & & Tilia sp. & Lime \\
\hline & & Ulmus sp. & Elm \\
\hline & & Cryptomeria japonica & Japanese cedar \\
\hline \multicolumn{4}{|l|}{ 2. Suggested homologous group: Oleaceae } \\
\hline Olea europaea & Olive & & \\
\hline Fraxinus excelsior & Ash & & \\
\hline Ligustrum vulgare & Privet & & \\
\hline Syringa vulgaris & Lilac & & \\
\hline \multicolumn{4}{|c|}{ 3. Suggested homologous group: Cupressaceae } \\
\hline Juniperus sp. & Juniper & & \\
\hline Cupressus sp. & Cypress & & \\
\hline \multicolumn{4}{|l|}{ Grass and cereal pollen } \\
\hline \multicolumn{2}{|c|}{$\begin{array}{l}\text { 4. Suggested homologous group: sweet grasses, the Poaceae (Gramineae) family, } \\
\text { Pooideae subfamily }\end{array}$} & \multicolumn{2}{|c|}{ Non-grouped species: justification for mixing required } \\
\hline Anthoxanthum odoratum & Sweet vernal grass & Cynodon dactylon & Bermuda grass \\
\hline Avena sativa & Oat & Cynosurus cristatus & Dogstail \\
\hline Dactylis glomerata & Orchard grass/cocksfoot & & \\
\hline Festuca sp. & Meadow fescue & & \\
\hline Holcus lanatus & Velvet grass/Yorkshire fog & & \\
\hline Hordeum vulgare & Barley & & \\
\hline Lolium perenne & Perennial ryegrass & & \\
\hline Phleum pratense & Timothy grass & & \\
\hline Poapratensis & Kentucky bluegrass & & \\
\hline Secale cereale & Cultivated rye & & \\
\hline Triticum aestivum & Cultivated wheat & & \\
\hline \multicolumn{4}{|c|}{ Additional Pooideae grass species, with reservations: } \\
\hline Agropyron sp. & Couch grass/crested wheatgrass & & \\
\hline Agrostis sp. & Bent grass & & \\
\hline Alopecurus pratensis & Meadow foxtail & & \\
\hline Arrhenatherum elatius & False oat & & \\
\hline Bromus sp. & Brome grass & & \\
\hline \multicolumn{4}{|l|}{ Weed pollen } \\
\hline \multicolumn{2}{|c|}{ 5. Suggested homologous group: weed pollen species } & \multicolumn{2}{|c|}{ Non-grouped species: justification for mixing required } \\
\hline Ambrosia artemisiifolia, Ambrosia trifida & Ragweed & Plantago sp. & Plantain \\
\hline Artemisia vulgaris & Mugwort & & \\
\hline Parietaria judaica, Parietaria officinalis & Pellitory & & \\
\hline \multicolumn{4}{|l|}{ MITES } \\
\hline \multicolumn{2}{|c|}{ 6. Suggested homologous group: house dust mites of the Dermatophagoides genus } & \multicolumn{2}{|c|}{ Non-grouped species: justification for mixing required } \\
\hline Dermatophagoides pteronyssinus & European house dust mite & Acarus siro & Flour mite \\
\hline Dermatophagoides farinae & American house dust mite & Glycyphagus domesticus & House mite \\
\hline
\end{tabular}


Table 2 continued

\begin{tabular}{|c|c|c|}
\hline \multirow[t]{2}{*}{ Homologous groups } & \multicolumn{2}{|l|}{ No homologous groups } \\
\hline & Lepidoglyphus destructor & Storage mite \\
\hline & Thyreophagus entomophagus & Flour mite \\
\hline & Tyrophagus putrescentiae & Storage mite \\
\hline Insect venoms & \multicolumn{2}{|c|}{ Non-grouped species: justification for mixing required } \\
\hline No homologous groups & \multicolumn{2}{|l|}{ All species } \\
\hline $\begin{array}{l}\text { Allergen extracts derived from vertebrates (extracts such as animal epithelia, } \\
\text { hair, dander) }\end{array}$ & \multicolumn{2}{|c|}{ Non-grouped species: justification for mixing required } \\
\hline \multirow[t]{8}{*}{ No homologous groups } & Canis familiaris & Dog \\
\hline & Felis domesticus & Cat \\
\hline & Cavia porcellus & Guinea pig \\
\hline & Cricetus cricetus & Hamster \\
\hline & Equus caballus & Horse \\
\hline & Mus musculus & Mouse \\
\hline & Oryctolagus cuniculus & Rabbit \\
\hline & Rattus sp. & Rat \\
\hline \multirow[t]{2}{*}{ Moulds } & \multicolumn{2}{|c|}{ Non-grouped species: justification for mixing required } \\
\hline & \multicolumn{2}{|l|}{ All species } \\
\hline No homologous groups & \multicolumn{2}{|c|}{$\begin{array}{l}\text { In case of justification of grouping of mould species, } \\
\text { special emphasis on similar stability is necessary }\end{array}$} \\
\hline
\end{tabular}

What is the clinical trial evidence for the efficacy and safety of multi-AIT in polyallergic patients?

Few well-designed, double-blinded, placebo-controlled studies have evaluated treatment with multi-allergen formulations [24, 31-34]. Accordingly, most meta-analyses published to date have evaluated AIT formulations containing a single allergen or several cross-reactive allergens, and have urged caution with regard to multi-AIT. However, multi-AIT is common practice in the majority of allergists' practices in the USA and in $20-40 \%$ of the prescriptions in Europe [22]. This approach needs more supporting data from large clinical trials before it can be validated as a treatment option in polyallergic patients [23, 31]. Although some clinical studies of multi-AIT have clearly demonstrated efficacy, the thousands of different mixtures used worldwide have not been sufficiently investigated. A review by Nelson identified 13 studies (published between 1965 and 2007) in which two or more unrelated allergens were simultaneously administered as subcutaneous allergen immunotherapy (SCIT, 11 studies) or as SLIT (two studies) [32]. Nelson concluded that sublingual or subcutaneous administration of two simultaneous extracts was effective, on the basis of four studies reporting greater efficacy than placebo or much the same efficacy as single-AIT. Only seven of the trials were double-blind, placebo-controlled, randomized trials; it is obvious that most of these would not meet current standards for pivotal trials for regulatory approval.
What is the real-life evidence for the efficacy and safety of AIT in polyallergic patients?

"Real-life" clinical practice in the diagnosis of respiratory allergy and its management with AIT varies from one country to another. When AIT is prescribed, some allergists tend to treat the polyallergic patient with a singleallergen formulation (using the most clinically relevant allergen), whereas others prescribe either a mixture of two or more allergen extracts or two or more separate allergen extracts. Real-life observational and post-marketing studies show that AIT is safe and effective in polyallergic patients. Although very few observational surveys have been performed in allergists' practices in Europe, the published data are very instructive. In a French study of 2434 polysensitized patients [35] reported that AIT was prescribed to $84.3 \%$ of the patients. Of those who received AIT, $72.5 \%$ were receiving a single formulation. When a single formulation was used, it was usually a single extract (in $86 \%$ of cases) or, less frequently, a mixture of two allergen extracts $(12.8 \%)$ or three or more extracts (1.1\%). For patients receiving two AIT formulations, each was almost always a single-allergen extract (in $97 \%$ of these cases). Furthermore, the results of two open, prospective, observational studies in Germany demonstrated that (1) polyallergic patients benefited as much from 300IR SLIT birch as monoallergic patients did and (2) in polyallergic patients treated with a 5 -grass pollen extract, tolerability and symptom relief did not depend on the concomitant use of other allergen extracts [36, 37]. 
Ciprandi et al. prospectively evaluated a group of 87 adult patients (mean \pm standard deviation age: $29.7 \pm 10.8$ ) with AR and/or mild-to-moderate AA [38]. The mean number of sensitizations per patient was 3.5 , and the most frequent sensitizing allergens were grass pollen (64.4\%), house dust mites (HDMs) (46\%) and Parietaria pollen (36.8\%). Fifty-nine patients $(67.8 \%)$ were treated with single-allergen SLIT and 28 (32.2\%) were treated with 2-allergen SLIT. Importantly, there was no difference in the clinical outcomes (symptom severity, rhinitis classification and QoL) between these two treatment groups. Similar results were found in 51 polysensitized children (mean age: 11.8) with AR and/or mild-to-moderate AA [39]. One, two and three allergens were prescribed in 82,8 and $6 \%$ of cases, respectively (with missing data in $4 \%$ ). One year of SLIT was associated with significant reductions in ocular, nasal, and bronchial symptom scores $(\mathrm{p}<0.01)$ and rescue medication use ( $\mathrm{p}<0.01)$, relative to pre-treatment values [39].

Hence, in surveys of real-life clinical practice, allergy specialists appear to consider that polysensitization per se does not influence the indications for AIT [12, 35, 40]. One should remind that the interpretation of adverse reactions maybe challenging: the culprit allergen is difficult to identify when a mixture is administered.

Although prescribing AIT in polysensitized patients (who may be monoallergic or polyallergic) is not a problem for trained clinicians with experience in allergy, the management approaches are not standardized and there is no clear-cut decision tree to assist clinicians in their provision of high-quality care. In general, the absence of clear guidelines and practice parameters has prompted physicians to shy away from prescribing AIT to polyallergy patients.

\section{A practice-based approach}

We asked the group the following questions and moved forward by consensus:

1. How can be a polyallergic patient be identified?

2. When is AIT with a single allergen source indicated?

3. When AIT is with two allergen sources indicated (mixtures or two parallel course of AIT)?

4. When should two allergen sources be administered concomitantly?

5. How should two allergen sources be administered sequentially?

6. Can SLIT be combined with SCIT for 2-allergen immunotherapy?

7. When is AIT with three or more allergen sources indicated?

8. Are there specific issues to be considered when treating the most frequent polyallergic profiles?
9. Are there any other specific considerations?

\section{How can be a polyallergic patient be identified?}

Two main diagnostic methods are at our disposal: SPTs and ssIgE assays, both of which can only demonstrate the patient's sensitization to an allergen source. These results must be cross-correlated with the clinician's clinical interpretation, so as to identify the allergen(s) associated with a clinical and QoL impact (based on the GA ${ }^{2} L E N$ recommendations) [23].

Although allergen challenges (i.e. a nasal challenge, a conjunctival challenge or exposure in a challenge chamber) can reproducibly demonstrate the clinical relevance of a given sensitization, they are difficult to perform [41]. Furthermore, the SPT wheal diameter and ssIgE titre are of limited value for identifying clinically relevant causal allergens at the patient level, although they are very useful at the population level [42]. In contrast, component resolved diagnosis (CRD) may help the physician to identify clinically relevant causal allergens and to distinguish genuine polysensitization ("co-sensitization") from polysensitization due to cross-reactivity ("cross-sensitization") (Table 1). It is now clear that molecular diagnosis can help to tailor the individual AIT [43-48], and it was recently shown that the levels of ssIgE against Par $j 2$ and Bet $\mathrm{v} 1$ may distinguish between sensitization and allergy $[49,50]$. Furthermore, it has been reported that ssIgE levels may predict the clinical response to AIT [51-53].

In particular, it is important to identify the allergen source(s) which most impact(s) QoL when allergies to two or more allergens from different homologous groups are diagnosed (e.g. grass pollen + HDM). Polyallergic patients will necessarily be polysensitized; the physician's key task is to establish which of the sensitizing allergens are relevant with regard to the clinical symptoms of allergy. We consider that a patient's clinical history alone is often (but not always) enough to identify the clinically relevant allergen in allergic respiratory disease, although it remains sufficient for an aetiological diagnosis in most cases. By way of an example, Crobach et al. reported that when considering a diagnosis of $\mathrm{AR}$, the predictive value of the clinical history alone was $82-85 \%$ for seasonal allergens and at least $77 \%$ for perennial allergens [54]. These values increased to 97-99\% when both SPT and ssIgE data were available for a given patient.

Following identification of the most clinically relevant allergen, the physician's next decision is how to treat the polyallergic patient.

\section{When is AIT with a single allergen source indicated?}

Single-AIT is recommended in polyallergic patients in whom one of several relevant allergens is nevertheless clearly responsible for the most intense and/or 


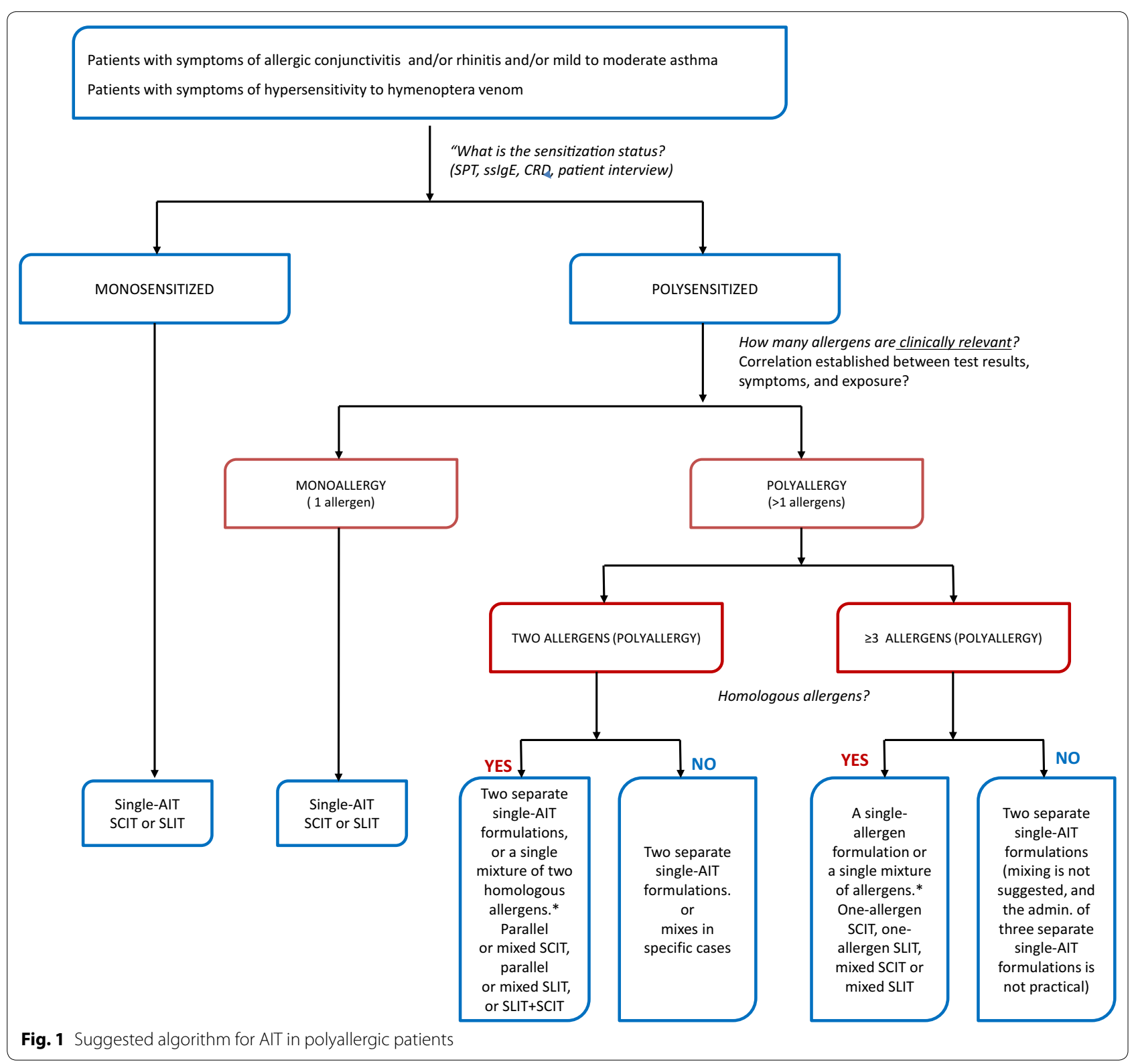

bothersome symptoms. Again, the physician should identify this allergen on the basis of symptom intensity, impact on QoL, the duration of symptoms, and the ability to avoid allergens [23]. To facilitate the physician's task, we have developed a treatment decision tree (Fig. 1). When selecting a treatment, patient preferences in relation to the administration route, adherence and cost, and the availability of high-quality AIT formulations must be taken into account.

Within a homologous group (such as Dermatophagoides species, Pooideae pollens or Betulaceae pollens), the use of a single course of AIT with a mixture of allergens that mimics natural exposure is recommended (e.g. a Dermatophagoides pteronyssinus/Dermatophagoides farinae mixture, a grass mixture or a birch/hazel/nut mixture). Patients are exposed and sensitized to allergen isoforms originating from two or more species in the group, and thus patients develop antibody and $\mathrm{T}$ cell responses to both cross-reactive (conserved) and noncross-reactive (species-specific) epitopes. Therefore, a mixture of both species provides a broad spectrum of allergens and thus $\mathrm{B}$ and $\mathrm{T}$ cell epitopes for optimal reprogramming of the immune system [55].

Sublingual immunotherapy with one or several extracts was safe and effective in improving allergy-related outcomes [40, 56-61] (including a global asthma score, an 
asthma medication consumption score [59] and a healthrelated QoL score [56]) in both children [39] and adults aged 50 and over [58].

\section{When is AIT with two allergen sources indicated (mixtures or two parallel courses of AIT)?}

Parallel 2-allergen immunotherapy or mixed 2-allergen immunotherapy is indicated in polyallergic patients in whom two causal relevant allergens have a marked clinical and QoL impact. Our recommendations for the choice of AIT modality as a function of the clinically relevant allergen are summarized in Table 3. Treatment adherence and cost are both issues that may influence the physician's decision to prescribe 2-allergen immunotherapy rather than a mixture. Should 2-allergen immunotherapy be indicated, it should preferably be administered as two standardized, single-AIT formulations in parallel (see below). Mixing of allergen extracts may be considered, as long as (1) the mixture is technically feasible (according to good manufacturing practice),
(2) the mixture is allowed from a regulatory standpoint, (3) the various components are present at a concentration for which efficacy has been clearly demonstrated, and (4) the individual allergen doses in a mixture are adjusted (e.g. 1/2 of allergen source 1 and $1 / 2$ of allergen source 2 in a two-allergen source mixture; $1 / 3$ of allergen source $1,1 / 3$ of allergen source 2 and $1 / 3$ of allergen source 3 in a three-allergen source mixture, etc). There is no scientific rationale for adjusting the mixing ratio mixture as a function of diagnostic test results, since the latter are not linked to clinical manifestations. However, mixing several allergen extracts is associated with a risk of (1) proteolytic degradation (as mentioned by the EMA) and (2) possible antigenic competition, due to saturation of the immune system's allergen processing pathways at the administration site $[24,28,62]$. Although the latter subject requires further study, it has been reported that antigenic competition affects the immunogenicity and efficacy of injectable paediatric vaccines with antigens from six infectious pathogens [63].

Table 3 Recommendations if the patient is allergic to two clinically relevant allergens

\begin{tabular}{|c|c|c|c|c|c|c|c|c|c|}
\hline $\begin{array}{c}\text { Allergens } \\
\text { (homologous } \\
\text { group) }\end{array}$ & $\begin{array}{l}\text { Birch group or } \\
\text { 'fagales } \\
\text { group' }\end{array}$ & Oleaceae & Cupressaceae & $\begin{array}{c}\text { Grasses and } \\
\text { cereal } \\
\text { (Pooideae) }\end{array}$ & Weed pollen & $\begin{array}{c}\text { Mites } \\
\text { (different } \\
\text { sources ) }\end{array}$ & Venom & Danders & Moulds \\
\hline $\begin{array}{l}\text { Birch group or } \\
\text { fagales group' }\end{array}$ & 1 AIT & $\begin{array}{l}2 \text { AIT and/or } \\
\text { mixtures }\end{array}$ & $\begin{array}{l}2 \text { AIT and/or } \\
\text { mixtures }\end{array}$ & $\begin{array}{l}2 \text { AIT and/or } \\
\text { mixtures }\end{array}$ & $\begin{array}{l}2 \text { AIT and/or } \\
\text { mixtures }\end{array}$ & 2 AIT & 2 AIT & 2 AIT & 2 AIT \\
\hline Oleaceae & $\begin{array}{l}2 \text { AIT and/or } \\
\text { mixtures }\end{array}$ & 1 AIT & $\begin{array}{l}2 \text { AIT and/or } \\
\text { mixtures }\end{array}$ & $\begin{array}{l}2 \text { AIT and/or } \\
\text { mixtures }\end{array}$ & $\begin{array}{l}2 \text { AIT and/or } \\
\text { mixtures }\end{array}$ & 2 AIT & 2 AIT & 2 AIT & 2 AIT \\
\hline Cupressaceae & $\begin{array}{c}2 \text { AIT and/or } \\
\text { mixtures }\end{array}$ & $\begin{array}{l}2 \text { AIT and/or } \\
\text { mixtures }\end{array}$ & 1 AIT & $\begin{array}{l}2 \text { AIT and/or } \\
\text { mixtures }\end{array}$ & $\begin{array}{l}2 \text { AIT and/or } \\
\text { mixtures }\end{array}$ & 2 AIT & 2 AIT & 2 AIT & 2 AIT \\
\hline $\begin{array}{c}\text { Grasses and } \\
\text { cereal } \\
\text { (Pooideae) }\end{array}$ & $\begin{array}{l}2 \text { AIT and/or } \\
\text { mixtures }\end{array}$ & $\begin{array}{c}2 \text { AIT and/or } \\
\text { mixtures }\end{array}$ & $\begin{array}{l}2 \text { AIT and/or } \\
\text { mixtures }\end{array}$ & 1 AIT & $\begin{array}{l}2 \text { AIT and/or } \\
\text { mixtures }\end{array}$ & 2 AIT & 2 AIT & 2 AIT & 2 AIT \\
\hline Weed pollen & $\begin{array}{l}2 \text { AIT and/or } \\
\text { mixtures }\end{array}$ & $\begin{array}{l}2 \text { AIT and/or } \\
\text { mixtures }\end{array}$ & $\begin{array}{l}2 \text { AIT and/or } \\
\text { mixtures }\end{array}$ & $\begin{array}{l}2 \text { AIT and/or } \\
\text { mixtures }\end{array}$ & 1 AIT & 2 AIT & 2 AIT & 2 AIT & 2 AIT \\
\hline $\begin{array}{l}\text { Mites (different } \\
\text { sources ) }\end{array}$ & 2 AIT & 2 AIT & 2 AIT & 2 AIT & 2 AIT & $\begin{array}{l}2 \text { AIT and/or } \\
\text { mixtures }\end{array}$ & 2 AIT & 2 AIT & 2 AIT \\
\hline Venom & 2 AIT & 2 AIT & 2 AIT & 2 AIT & 2 AIT & 2 AIT & 2 AIT & 2 AIT & $2 \mathrm{AIT}$ \\
\hline Danders & 2 AIT & 2 AIT & 2 AIT & 2 AIT & 2 AIT & 2 AIT & 2 AIT & 2 AIT & $2 \mathrm{AIT}$ \\
\hline Moulds & 2 AIT & 2 AIT & 2 AIT & 2 AIT & 2 AIT & 2 AIT & 2 AIT & 2 AIT & 2 AIT \\
\hline
\end{tabular}


Good adherence is a prerequisite for efficacy (regardless of the type of medication, and notably for AIT [64]), and so increasing the complexity of the treatment regimen will accentuate the importance of this parameter [65]. Likewise, two parallel courses of AIT will necessarily increase the cost of the treatments and associated procedures. Hence, cost and adherence issues may sometimes mean that two parallel courses of AIT are not indicated in a particular polyallergic patient; in some circumstances, a mixture might be an appropriate option.

\section{How should two allergen sources be administered concomitantly?}

Two-allergen immunotherapy can be administered as (1) a single mixture of two extracts (mixed multi-AIT, Table 1), with the standard ratio of each allergen source, or (2) two separate but simultaneous courses of one-allergen immunotherapy (parallel multi-AIT, Table 1). Use of separate AIT formulations is preferable when treating with two non-homologous allergens (as defined by the EMA). Most cases of polyallergy requiring the simultaneous administration of two clinically relevant allergens will involve non-homologous allergens (such as grass pollen $+\mathrm{HDMs}$ ), rather than homologous allergens (such as olive pollen and ash pollen).

For SLIT (given its excellent safety profile), we recommend administering two separate SLIT formulations in the morning with an interval of $30 \mathrm{~min}$ (or one in the morning and one later on in the day). Although there may be an immune saturation effect at the oral mucosa $[24,62]$, this potential issue is avoided by ensuring an interval of $30 \mathrm{~min}$ between administrations of SLIT formulations. For SCIT, quasi-simultaneous injections at different sites/arms are commonly used by some experienced practitioners. However, the recommended 30-min observation period after each injection remains essential as a way of determining the responsibility of a particular allergen extract if adverse events occur.

There are few robust studies on the efficacy of mixed multi-AIT vs. parallel multi-AIT or on parallel vs. sequential administration [30]. Despite the absence of clinical trial results supporting the use of mixed allergens, there are no immunological reasons why a 2-allergen extract of homologous groups or two separate one-allergen extracts would lack efficacy.

\section{When should two allergen sources be administered sequentially?}

Allergen immunotherapy should be initiated first for the most clinically relevant allergen, then a subsequent course with the second more important allergen can be considered, at least 1 year after. Therefore we are speaking of 6 years at most.
However, lack of good adherence is a problem with both SCIT and SLIT when considered in terms of completing courses of therapy.

\section{Can SLIT be combined with SCIT for 2-allergen immunotherapy?}

A combination of SCIT and SLIT may be appropriate, subject to the patient's preference and level of adherence, and the nature of the allergen source. For example, SCIT with a perennial allergen source and pre- and co-seasonal SLIT with a seasonal allergen will reduce the overall number of administrations. Both SLIT and SCIT are safe and effective when correctly prescribed and appropriately administered. By analogy with single-AIT (see above), the physician and the patient will decide together on the most appropriate administration route, as a function of personal preference and the availability of highquality AIT formulations. However, if SLIT (or SCIT) is chosen because it is likely to be safe, effective and convenient for one course of treatment, it is likely to be so for a second course of treatment.

\section{When is AIT with three or more allergen sources indicated?}

We recommend focusing on the two most clinically relevant allergen sources. Hence, AIT with three or more allergen sources should only be considered in the very rare cases in which (1) all the allergens clearly cause severe symptoms and (2) a definitive molecular diagnosis (with CRD) is available prior to initiation of AIT. Even then, the physician should consider very carefully whether sequential treatments with a single-allergen formulation or several single-allergen formulations in parallel (together with on-demand symptomatic medications) will in fact be enough to provide the patient with adequate symptom relief. If AIT with three or more allergens is considered, its administration should follow the guidance given above for 2-allergen immunotherapy (i.e. administration at different times and body sites).

Prescriptions of AIT with three or more allergen sources are rare in European countries (and thus few data are available) but very common in the US [35]. In observational surveys in France, only $1.1 \%$ of AIT prescriptions contained three or more allergen sources [36]. If a mixture of three or more allergen sources has to be used, individual doses must be adapted as described above, and this is likely to impact efficacy.

\section{Are there specific issues to be considered when treating the most frequent polyallergic profiles?}

Based on our experience in our respective countries, the following patient profiles will be most commonly concerned by the present guidance. In Europe, grass pollen + birch pollen is the most common polyallergic 
profile, followed by pollens + HDM. In a study in France, the most frequent polyallergy combinations were grass pollen-HDM (16.9\%), grass pollen-tree pollens (12.2\%), HDM-dander (10.6 \%), HDM-dander-grass pollen (9 \%), and HDM-tree pollen-grass pollens (8.1\%), albeit with regional variations. $76 \%$ of the polyallergic patients presented with both seasonal and perennial allergies, $13 \%$ suffered from perennial allergies only and $11 \%$ suffered from seasonal allergies only [36].

The most common combinations of allergies in Germany are grass pollen + birch, grass pollen + HDMs, and tree pollen + HDMs; one should be aware that in Germany, mixing any other extract with a grass pollen, tree pollen or HDM extract would then mean that the resulting mixture becomes subject to the German Therapy Allergen Ordinance and thus would have to be approved by the regulatory authorities $[66,67]$. In Italy, the most common combinations are grass pollen + HDMs, grass pollen + Parietaria pollen; HDMs + Parietaria pollen, grass pollen + birch pollen. In Spain, the most common combinations are grass pollen + olive pollen; grass pollen + Cupressus sp. pollen, Salsola pollen + grass pollen, Cupressus sp. pollen + olive pollen, grass pollen + Parietaria pollen, Dermatophagoides sp. + Blomia tropicalis and Dermatophagoides sp. + Lepidoglyphus destructor.

\section{Are there any other specific considerations?}

The physician must consider allergens such as the mite Blomia tropicalis, the subtropical Chloridoideae subfamily of grasses (e.g. Cynodon dactylon, Bermuda grass) and the Panicoideae subfamily of grasses (e.g. Paspalum notatum, Bahia grass)-especially for regional allergens or in (sub)tropical areas.

Ragweed pollen is a highly allergenic agent in some regions of Italy, France and eastern European countries.

Alternaria mould is also sometimes an issue (particularly in Spain), and so more studies of mould allergies are needed. With regard to animal dander, there is concern as to whether the doses of allergens in extracts are sufficiently high. Cockroaches and occupational allergens may be important in a few cases, although extracts are poorly standardized. In subtropical areas, the mite Blomia tropicalis has clear clinical relevance, and cross-reactivity with Dermatophagoides allergens is only partial. Cynodon dactylon may also be important and has limited cross-reactivity with the Pooideae [68]. These allergen sources deserve a thorough analysis of the literature and the provision of advice from experts in exposed areas.

\section{Conclusions}

We recommend single-AIT in (1) polyallergic patients with a seasonal allergy to one allergen source and perennial allergy to another allergen, and (2) polyallergic patients in whom one of the several relevant allergens is clearly responsible for the most intense and/or bothersome symptoms. We recommended parallel or mixed 2-allergen immunotherapy only for patients in whom two allergens have similar, significant clinical and QoL impacts that overlap in time. When prescribed, 2-allergen immunotherapy should preferably consist of the separate administration of two high-quality, standardized, single-allergen formulations; this is highly preferable for non-homologous allergens. Simultaneous treatment with three or more allergens is rarely going to be clinically relevant. If a mixture has to be used, there is no reason for varying the ratios between the individual allergen sources (e.g. one should always use $1 / 2$ of allergen source 1 and $1 / 2$ of allergen source 2 in a two-allergen mixture; $1 / 3$ of allergen source $1,1 / 3$ of allergen source 2 and $1 / 3$ of allergen source 3 in a three-allergen mixture, etc), while ensuring that each of the components is still present at a concentration for which efficacy has been clearly demonstrated. All these preparations should used high-quality, evidence-supported and well standardized extracts as required by the World Allergy Organization [69].

\section{Abbreviations}

AA: allergic asthma; AlT: allergen immunotherapy; AR: allergic rhinitis; CRD: component-resolved diagnosis; EAACl: European Academy of Allergy and Clinical Immunology; EMA: European Medicines Agency; GA²LEN: Global Allergy and Asthma European Network; IgE: immunoglobulin E; HDM: house dust mite; SCIT: subcutaneous allergen immunotherapy; SLIT: sublingual allergen immunotherapy; SPT: skin prick test; sslgE: serum specific immunoglobulin E.

\section{Authors' contributions}

All the authors conceived the practice-based approach, analyzed the situation and draft the manuscript. All authors read and approved the final manuscript.

\section{Author details}

${ }^{1}$ Division of Allergy, Department of Pulmonology, Hôpital Arnaud de Villeneuve, University Hospital of Montpellier, Montpellier, France. ${ }^{2}$ Sorbonne Universités, UPMC Paris 06, UMR-S 1136, IPLESP, Equipe EPAR, Paris, France. ${ }^{3}$ Allergy and Respiratory Diseases, IRCCS San Martino-IST, University of Genoa, Genoa, Italy. ${ }^{4}$ Center for Rhinology and Allergology, Wiesbaden, Germany. ${ }^{5}$ Department of Otorhinolaryngology, Head and Neck Surgery, Medical Faculty Mannheim, Universitatsmedizin Mannheim, Heidelberg University, Mannheim, Germany. ${ }^{6}$ Allergy Division, Fundación Jimenez Díaz, Madrid, Spain. ${ }^{7}$ Department of Paediatric Pulmonology and Immunology, Charité Virchow-Klinikum, Humboldt University, Berlin, Germany.

\section{Acknowledgements}

We thank David Fraser D.Phil. (Biotech Communication SARL, Damery, France), and Catherine Bos who provides medical writing services on behalf of Stallergenes. The present work was developed with an unrestricted grant from Stallergenes.

\section{Competing interests}

Pascal Demoly is a consultant and a speaker for Stallergenes, Circassia, ALK and Chiesi and was a speaker for Merck, Astra Zeneca, Pierre Fabre Médicaments, Menarini, Allergopharma and GlaxoSmithKline in 2010-2015. Giovanni Passalacqua is a consultant and speaker for Stallergenes, Lofarma, and has been a speaker for Allergopharma, ALK-Abellò, Chiesi, Novartis, GSK. Oliver Pfaar has received research grants for his institution from Allergopharma (Germany), ALK-Abello (Denmark), Stallergenes (France), HAL-Allergy (Netherlands), Artu Biologicals (Netherlands), Allergy Therapeutics/Bencard (United Kingdom/ 
Germany), Hartington (Spain), Lofarma (Italy), Novartis/Leti (Germany/Spain), GlaxoSmithKline (United Kingdom), Essex-Pharma (Germany), Cytos (Switzerland), Curalogic (Denmark), Roxall (Germany), Biomay (Austria), ThermoFisher (USA), Circassia (United Kingdom), E.U (FP-7-Health-2013-Innovation 1), Biotech Tools (Belgium) and MEDA-Pharma (Sweden) He has received personal payments as consultant for Allergopharma (Germany), Anergis (Switzerland), Bencard (Germany), HAL-Allergy (Netherlands), Novartis/LETI (Germany), MEDA-Pharma (Germany), ALK-Abello (Denmark), Biotech Tools (Belgium), GFK Bridgehead (United Kingdom), NAVIGANT-consulting (USA), Sanofi (USA), Guidepoint Global Advisors (USA), Pohl-Boskamp (Germany), Stallergenes (France), Mobile Chamber Experts (a GA²LEN partner, Germany). He has received personal payments for lectures, book chapters or educational presentations from ALK-Abello (Denmark), Allergopharma (Germany), Stallergenes (France), HAL-Allergy (Germany/Netherlands), Allergy Therapeutics/ Bencard (United Kingdom/Germany), Hartington (Spain), Lofarma (Italy), Novartis/Leti (Germany/Spain), GlaxoSmithKline (Germany), Roxall (Germany), Thermo-Fisher (Germany), MEDA-Pharma (Germany), Schattauer (Germany), Springer (Germany) and GlaxoSmithKline (Germany). He has served as advisor and on the speakers' bureaus for some of the aforementioned companies. He has received travel grants from HAL-Allergy (Netherlands), Allergopharma (Germany), the European Academy of Allergy and Clinical Immunology (EAACI), the German Society for Allergology and Clinical Immunology (DGAKI) and the German Respiratory Society (DGP). He is the current chairman of the Immunotherapy Interest Group (IT IG) of EAACl and is the secretary of the ENT section of DGAKI. Joaquín Sastre reports having served as a consultant to Thermofisher, MSD, Novartis, Gennetech, Sanofi, Leti, Roche, FAES FARMA, and GSK; having been paid lecture fees by Novartis, GSK, Stallergenes, LETI, FAES FARMA as well as having received grant support for research from Thermofisher, GSK, and ALK-Abello. Ulrich Wahn has received consulting fees from Stallergenes Merck, Allergopharma, Danone, Hipp, Novartis, honoraria for lectures funding from ALK, Allergy Therapeutics, Stallergenes, Allergopharma, Nestle, Nutricia, Novartis, MSD, Leti and/research funding from Stallergenes.

Received: 23 October 2015 Accepted: 22 December 2015 Published online: 11 January 2016

\section{References}

1. Bauchau V, Durham SR. Epidemiological characterization of the intermittent and persistent types of allergic rhinitis. Allergy. 2005;60:350-3.

2. Bousquet J, Van CP, Khaltaev N, ARIA Workshop Group, World Health Organization. Allergic rhinitis and its impact on asthma. J Allergy Clin Immunol. 2001;108:S147-334.

3. Bousquet J, Khaltaev N, Cruz AA, Denburg J, Fokkens WJ, Togias A, et al. Allergic rhinitis and its impact on asthma (ARIA) 2008 update (in collaboration with the World Health Organization, GA²LEN and AllerGen). Allergy. 2008;63:58-160.

4. Brozek JL, Bousquet J, Baena-Cagnani CE, Bonini S, Canonica GW, Casale TB, et al. Allergic rhinitis and its impact on asthma (ARIA) guidelines: 2010 revision. J Allergy Clin Immunol. 2010;126:466-76.

5. Canonica GW, Bousquet J, Casale T, Lockey RF, Baena-Cagnani CE, Pawankar R, et al. Sub-lingual immunotherapy: World Allergy Organization position paper 2009. Allergy. 2009;64(Suppl 91):1-59.

6. Canonica GW, Cox L, Pawankar R, Baena-Cagnani CE, Blaiss M, Bonini S, et al. Sublingual immunotherapy: World Allergy Organization position paper 2013 update. World Allergy Organ J. 2014;7:6. doi:10.1186/1939-4551-7-6.

7. Bousquet PJ, Castelli C, Daures JP, Heinrich J, Hooper R, Sunyer J, et al. Assessment of allergen sensitization in a general population-based survey (European Community Respiratory Health Survey I). Ann Epidemiol. 2010;20:797-803

8. Arbes SJ Jr, Gergen PJ, Elliott L, Zeldin DC. Prevalences of positive skin test responses to 10 common allergens in the US population: results from the third National Health and Nutrition Examination Survey. J Allergy Clin Immunol. 2005;116:377-83.

9. Craig TJ, King TS, Lemanske RF Jr, Wechsler ME, Icitovic N, Zimmerman RR Jr, et al. Aeroallergen sensitization correlates with PC(20) and exhaled nitric oxide in subjects with mild-to-moderate asthma. J Allergy Clin Immunol. 2008;121:671-7.
10. Worm M, Lee HH, Kostev K. Prevalence and treatment profile of patients with grass pollen and house dust mite allergy. J Dtsch Dermatol Ges. 2013;11(7):653-61.

11. Migueres M, Fontaine JF, Haddad T, Grosclaude M, Saint-Martin F, Bem David D, et al. Characteristics of patients with respiratory allergy in France and factors influencing immunotherapy prescription: a prospective observational study (REALIS). Int J Immunopathol Pharmacol. 2011;24(2):387-400.

12. Didier A, Chartier A, Démonet G. Immunothérapie sublinguale : pour quel profil de patients en pratique? Analyse intermédiaire d'Odissee (observatoire de l'indication, du choix de prise en charge par immunothérapie spécifique sublinguale ainsi que de l'adhésion et de l'observance au traitement chez les patients souffrant d'allergie respiratoire [rhinite et/ou conjonctivite et/ou asthme allergique]) = Specific sublingual immunotherapy: for which profiles of patients in practice? Midterm analysis of ODISSEE (observatory of the indication and management of respiratory allergies [rhinitis and/or conjunctivitis and/or allergic asthma] by specific sublingual immunotherapy). Revue Française d'Allergologie. 2010;50:426-33.

13. Didier A, Chartier A, Démonet G. Immunothérapie spécifique sublinguale : ODISSEE un an après. Résultats préliminaires d'ODISSEE (Observatoire de I'indication, du choix de prise en charge par Immunothérapie spécifique sublinguale ainsi que de l'adhésion et de l'observance au traitement chez les patients souffrant d'allergie respiratoire-rhinite et/ou conjonctivite et/ou asthme allergique) = Specific sublingual Immunotherapy: ODISSEE after one year. Preliminary results of ODISSEE (observatory of the indication and management of respiratory allergies rhinitis and/or conjunctivitis and/or allergic asthma by specific sublingual immunotherapy). Revue Française d'Allergologie 2011;51:476-84.

14. Langen U. Asthma and sensitization pattern in Children. In: Pereira C, editor. Allergic diseases-highlights in the clinic, mechanisms and treatment. ISBN: 978-953-51-0227-4. Rijeka, Croatia: InTech. 2012. http://www.intechopen.com/books/allergicdiseases-highlights-in-the-clinic-mechanisms-andtreatment/ asthma-and-sensitization-pattern-in-children.

15. Illi S, von Mutius E, Lau S, Niggemann B, Grüber C, Wahn U, Multicentre Allergy Study (MAS) group. Perennial allergen sensitisation early in life and chronic asthma in children: a birth cohort study. Lancet. 2006;368(9537):763-70.

16. Custovic A, Sonntag HJ, Buchan IE, Belgrave D, Simpson A, Prosperi MC. Evolution pathways of IgE responses to grass and mite allergens throughout childhood. J Allergy Clin Immunol. 2015;136(6):1645-52.e8.

17. Simpson A, Lazic N, Belgrave DC, Johnson P, Bishop C, et al. Patterns of IgE responses to multiple allergen components and clinical symptoms at age 11 years. J Allergy Clin Immunol. 2015;136(5):1224-31.

18. Westman M, Lupinek C, Bousquet J, Andersson N, Pahr S, Baar A, et al. Mechanisms for the development of allergies consortium. Early childhood IgE reactivity to pathogenesis-related class 10 proteins predicts allergic rhinitis in adolescence. J Allergy Clin Immunol. 2015;135:1199_ 206.e1-11.

19. Ciprandi G, Alesina R, Ariano R, Aurnia P, Borrelli P, Cadario G, et al. Characteristics of patients with allergic polysensitization: the POLISMAIL study. Eur Ann Allergy Clin Immunol. 2008;40(3):77-83.

20. Jutel M, Agache I, Bonini S, Burks AW, Calderon M, Canonica W, et al. International consensus on allergy immunotherapy. J Allergy Clin Immunol. 2015;136:556-68. doi:10.1016/j.jaci.2015.04.047 (Epub 2015 Jul 7).

21. Cox L, Nelson H, Lockey R, Calabria C, Chacko T, et al. Allergen immunotherapy: a practice parameter third update. J Allergy Clin Immunol. 2011;127(1 Suppl):S1-55.

22. Cox L, Jacobsen L. Comparison of allergen immunotherapy practice patterns in the United States and Europe. Ann Allergy Asthma Immunol. 2009;103:451-9.

23. Zuberbier T, Bachert C, Bousquet PJ, Passalacqua G, Canonica W, Merk H, et al. GA2LEN/EAACI pocket guide for allergen-specific immunotherapy for allergic rhinitis and asthma. Allergy. 2010;65:1525-30.

24. Calderón MA, Cox L, Casale TB, Moingeon P, Demoly P. Multiple-allergen and single-allergen immunotherapy strategies in polysensitized patients: looking at the published evidence. J Allergy Clin Immunol. 2012;129:929-34.

25. Migueres M, Dávila I, Frati F, Azpeitia A, Jeanpetit Y, Lhéritier-Barrand M, et al. Types of sensitization to aeroallergens: definitions, prevalences and 
impact on the diagnosis and treatment of allergic respiratory disease. Clin Transl Allergy. 2014;4:16.

26. Ciprandi G, Cirillo I. Monosensitization and polysensitization in allergic rhinitis. Eur J Intern Med. 2011;22:e75-9. doi:10.1016/j.ejim.2011.05.009

(Epub 2011 Jun 8)

27. Vidal C, Enrique E, Gonzalo A, Moreno C, Tabar Al, Expert Clinical Participants. Diagnosis and allergen immunotherapy treatment of polysensitised patients with respiratory allergy in Spain: an Allergists' Consensus. Clin Transl Allergy. 2014;4:36. doi:10.1186/2045-7022-4-36

28. European Medicines Agency. Guideline on allergen products: production and quality issues. London; 2008 EMEA/CHMP/BWP/304831/2007. http:// www.ema.europa.eu/docs/en_GB/document_library/Scientific_guideline/2009/09/WC500003333.pdf.

29. Lorenz AR, Lüttkopf D, May S, Scheurer S, Vieths S. The principle of homologous groups in regulatory affairs of allergen products-a proposal. Int Arch Allergy Immunol. 2009;148:1-17.

30. Cox L, Nelson H, Lockey R, Calabria C, Chacko T, Finegold I, et al. Allergen immunotherapy: a practice parameter third update. J Allergy Clin Immu nol. 2011;127(Suppl):S1-55.

31. Nelson HS. Multiallergen immunotherapy for allergic rhinitis and asthma. J Allergy Clin Immunol. 2009;123:763-9.

32. Calderon MA, Cox LS. Monoallergen sublingual immunotherapy versus multiallergen subcutaneous immunotherapy for allergic respiratory diseases: a debate during the AAAAl 2013 Annual Meeting in San Antonio, Texas. J Allergy Clin Immunol Pract. 2014;2:136-43.

33. Bahceciler NN, Galip N, Cobanoglu N. Multi allergen-specific immunotherapy in polysensitized patients: where are we? Immunotherapy. 2013;5:183-90.

34. Passalacqua $\mathrm{G}$. The use of single versus multiple antigens in specific allergen immunotherapy for allergic rhinitis: review of the evidence. Curr Opin Allergy Clin Immunol. 2014;14:20-4.

35. Pham-Thi N, Bousiquier P, Chartier A. Polysensibilisation aux pneumallergènes : étude des profils cliniques et des modalités de prescription d'immunothérapies. Quelle immunothérapie pour les patients polysensibilisés ? Résultats d'une enquête nationale des pratiques auprès des allergologues [Polysensitization to aeroallergens: Study of clinical profiles and immunotherapy modalities of prescription]. Revue Française d'Allergologie. 2012;52:3-10.

36. Hadler M, Karagiannis E, Shah-Hosseini K, Mösges R. Effectiveness and tolerability of a 2-year sublingual allergen immunotherapy (AIT) in routine medical practice in birch pollen allergic patients. Italy: Poster presented at the European Academy of Allergy and Clinical Immunology and World Allergy Organization Congress 2013 in Milan; 2013.

37. Shah-Hosseini K, Mioc K, Hadler M, Karagiannis E, Mösges R. Optimum treatment strategies for polyallergic patients - analysis of a large observational trial. Curr Med Res Opin. 2015;6:1-11.

38. Ciprandi G, Incorvaia C, Puccinelli P, Scurati S, Masieri S, Frati F. The POLISMAIL lesson: sublingual immunotherapy may be prescribed also in polysensitized patients. Int J Immunopathol Pharmacol. 2010;23:637-40.

39. Ciprandi G, Cadario GD, Gioacchino M, Gangemi S, Gasparini A, Isola S, et al. Sublingual immunotherapy in children with allergic polysensitization. Allergy Asthma Proc. 2010;31:227-31.

40. Ciprandi G, Incorvaia C, Puccinelli P, Soffia S, Scurati S, Frati F. Polysensitization as a challenge for the allergist: the suggestions provided by the polysensitization impact on allergen immunotherapy studies. Expert Opin Biol Ther. 2011;11:715-22. doi:10.1517/14712598.2011.576 246.

41. Pfaar O, Demoly P, Gerth van Wijk R, Bonini S, Bousquet J, Canonica GW, et al. Recommendations for the standardization of clinical outcomes used in allergen immunotherapy trials for allergic rhinoconjunctivitis: an EAACI position paper. Allergy. 2014;69:854-67.

42. Haahtela T, Burbach GJ, Bachert C, Bindslev-Jensen C, Bonini S, Bousquet $J$, et al. Clinical relevance is associated with allergen-specific wheal size in skin prick testing. Clin Exp Allergy. 2014;44:407-16. doi:10.1111/ cea.12240.

43. Sastre J, Landivar ME, Ruiz-García M, Andregnette-Rosigno MV, Mahillo I. How molecular diagnosis can change allergen-specific immunotherapy prescription in a complex pollen area. Allergy. 2012;67(5):709-11. doi:10.1111/j.1398-9995.2012.02808.x (Epub 2012 Mar 2).
44. Canonica GW, Ansotegui IJ, Pawankar R, Schmid-Grendelmeier P, van Hage M, Baena-Cagnani CE, et al. A WAO-ARIA-GA2LEN consensus document on molecular-based allergy diagnostics. World Allergy Organ J. 2013:6(1):17. doi:10.1186/1939-4551-6-17.

45. Douladiris N, Savvatianos S, Roumpedaki I, Skevaki C, Mitsias D, Papadopoulos NG. A molecular diagnostic algorithm to guide pollen immunotherapy in southern Europe: towards component-resolved management of allergic diseases. Int Arch Allergy Immunol. 2013;162(2):163-72. doi:10.1159/000353113 (Epub 2013 Jul 31).

46. Stringari G, Tripodi S, Caffarelli C, Dondi A, Asero R, Di Rienzo Businco A, et al. The effect of component-resolved diagnosis on specific immunotherapy prescription in children with hay fever. J Allergy Clin Immunol. 2014;134(1):75-81. doi:10.1016/j.jaci.2014.01.042 (Epub 2014 May 1)

47. Moreno C, Justicia JL, Quiralte J, Moreno-Ancillo A, Iglesias-Cadarso A, Torrecillas $M$, et al. Olive, grass or both? Molecular diagnosis for the allergen immunotherapy selection in polysensitized pollinic patients. Allergy. 2014;69:1357-63.

48. Darsow U, Brockow K, Pfab F, Jakob T, Petersson CJ, Borres MP, et al. Allergens. Heterogeneity of molecular sensitization profiles in grass pollen allergy-implications for immunotherapy? Clin Exp Allergy. 2014;44(5):778-86. doi:10.1111/cea.12303.

49. Comite P, Minale P, Ferrero F, Mussap M, Ciprandi G. Der p 1 lgE measurement for distinguishing between sensitization and allergy. Immunol Lett. 2015;166(2):145-6. doi:10.1016/j.imlet.2015.06.004.

50. Ciprandi G, Comite P, Ferrero F, Minale P, Voltolini S, Bignardi D, et al. Can serum white birch (Betula verrucosa) pollen antigen (Bet $v 1$ ) immunoglobulin E measurement distinguish between sensitization and allergy? Int Forum Allergy Rhinol. 2015; doi:10.1002/alr.21612

51. Ciprandi G, Alesina R, De Amici M. Serum specific lgE: biomarker for specific immunotherapy responsiveness? Allergol Immunopathol (Madr). 2014;42(4):369-71. doi:10.1016/j.aller.2012.12.004. (Epub 2013 Mar 6).

52. Tosca M, Silvestri M, Accogli A, Rossi GA, Ciprandi G. Serum-specific IgE and allergen immunotherapy in allergic children. Immunotherapy. 2014;6(1):29-33. doi:10.2217/imt.13.145.

53. Ciprandi $G$, Silvestri M. Serum specific IgE: a biomarker of response to allergen immunotherapy. J Investig Allergol Clin Immunol. 2014;24(1):35-9

54. Crobach MJ, Hermans J, Kaptein AA, Ridderikhoff J, Petri H, Mulder JD. The diagnosis of allergic rhinitis: how to combine the medical history with the results of radioallergosorbent tests and skin prick tests. Scand J Prim Health Care. 1998;16(1):30-6.

55. Moingeon P. Progress in the development of specific immunotherapies for house dust mite allergies. Expert Rev Vaccines. 2014;13:1463-73. doi:1 0.1586/14760584.2014.948861.

56. Ciprandi G, Cadario G, Di Gioacchino M, Gangemi S, Minelli M, Ridolo E, et al. Sublingual immunotherapy in polysensitized allergic patients with rhinitis and/or asthma: allergist choices and treatment efficacy. J Biol Regul Homeost Agents. 2009;23(3):165-71.

57. Ciprandi G, Cadario G, Valle C, Ridolo E, Verini M, Di Gioacchino M, et al Sublingual immunotherapy in polysensitized patients: effect on quality of life. J Investig Allergol Clin Immunol. 2010;20(4):274-9.

58. Bozek A, Kolodziejczyk K, Warkocka-Szoltysek B, Jarzab J. Grass pollen sublingual immunotherapy: a double-blind, placebo-controlled study in elderly patients with seasonal allergic rhinitis. Am J Rhinol Allergy. 2014;28:423-7. doi:10.2500/ajra.2014.28.4091.

59. Irani C, Saleh RA, Jammal M, Haddad F. High-dose sublingual immunotherapy in patients with uncontrolled allergic rhinitis sensitized to pollen: a real-life clinical study. Int Forum Allergy Rhinol. 2014;4(10):802-7.

60. Malling HJ, Montagut A, Melac M, Patriarca G, Panzner P, Seberova E, et al. Efficacy and safety of 5-grass pollen sublingual immunotherapy tablets in patients with different clinical profiles of allergic rhinoconjunctivitis. Clin Exp Allergy. 2009;39:387-93.

61. Nelson H, Blaiss M, Nolte H, Würtz $S \varnothing$, Andersen JS, Durham SR. Efficacy and safety of the SQ-standardized grass allergy immunotherapy tablet in mono- and polysensitized subjects. Allergy. 2013;68(2):252-5. doi:10.1111/all.12074 (Epub 2012 Dec 4).

62. Moingeon P. Update on immune mechanisms associated with sublingual immunotherapy: practical implications for the clinician. J Allergy Clin Immunol Pract. 2013;1(3):228-41. doi:10.1016/j.jaip.2013.03.013. (Epub 2013 Apr 29). 
63. Bar-On ES, Goldberg E, Fraser A, Vidal L, Hellmann S, Leibovici L. Combined DTP-HBV-HIB vaccine versus separately administered DTP-HBV and $\mathrm{HIB}$ vaccines for primary prevention of diphtheria, tetanus, pertussis, hepatitis B and Haemophilus influenzae B (HIB). Cochrane Database Syst Rev 2009;(3):CD005530.

64. Passalacqua G, Baiardini I, Senna G, Canonica GW. Adherence to pharmacological treatment and specific immunotherapy in allergic rhinitis. Clin Exp Allergy. 2013;43(1):22-8. doi:10.1111/j.1365-2222.2012.04052.x.

65. Reisacher WR, Visaya JM. Patient adherence to allergy immunotherapy. Curr Opin Otolaryngol Head Neck Surg. 2013;21(3):256-62. doi:10.1097/ MOO.0b013e32835f8048.

66. Kaul S, May S, Luttkopf D, Vieths S. Regulatory environment for allergenspecific immunotherapy. Allergy. 2011;66:753-64.

67. Pfaar O, Bachert C, Bufe A, Buhl R, Ebner C, Eng P, et al. Guideline on allergen-specific immunotherapy in IgE-mediated allergic diseases_-S2k. Guideline of the German Society for Allergology and Clinical Immunology (DGAKI), the Society for Pediatric Allergy and Environmental Medicine (GPA), the Medical Association of German Allergologists (AeDA), the
Austrian Society for Allergy and Immunology (ÖGAI), the Swiss Society for Allergy and Immunology (SGAI), the German Society of Dermatology (DDG), the German Society of Oto-Rhino-Laryngology, Head and Neck Surgery (DGHNO-KHC), the German Society of Pediatrics and Adolescent Medicine (DGKJ), the Society for Pediatric Pneumology (GPP), the German Respiratory Society (DGP), the German Association of ENT Surgeons (BV-HNO), the Professional Federation of Paediatricians and Youth Doctors (BVKJ), the Federal Association of Pulmonologists (BDP) and the German Dermatologists Association (BVDD). Allergo J Int. 2014;23:282-319.

68. Nony E, Bouley J, Le Mignon M, Lemoine P, Jain K, Horiot S, et al. Development and evaluation of a sublingual tablet based on recombinant Bet $\mathrm{V}$ 1 in birch pollen-allergic patients. Allergy. 2015;70:795-804. doi:10.1111/ all.12622.

69. Bachert C, Larché M, Bonini S, Canonica GW, Kündig T, Larenas-Linnemann D, et al. Allergen immunotherapy on the way to product-based evaluation—a WAO statement. World Allergy Organ J. 2015;8:2.

\section{Submit your next manuscript to BioMed Central and we will help you at every step:}

- We accept pre-submission inquiries

- Our selector tool helps you to find the most relevant journal

- We provide round the clock customer support

- Convenient online submission

- Thorough peer review

- Inclusion in PubMed and all major indexing services

- Maximum visibility for your research

Submit your manuscript at www.biomedcentral.com/submit
() Biomed Central 